\title{
humanidades
}

Revista humanidades

Enero-junio, 2016 • Volumen 6, número 1 • ISSN 2215-3934 • pp. 1-48

\section{"Crisis humanitaria": El rol de las redes sociales en el proceso migratorio de adolescentes migrantes}

DOI: http://dx.doi.org/10.15517/h.v6i1.25119

\section{Óscar Bernardo Rivera García}

Maestro en Ciencias Sociales por El Colegio Mexiquense A.C y Licenciado en Sociología por la Universidad Autónoma del Estado de México. Alumno de Doctorado en Ciencias Sociales en el Colegio de Sonora, Hermosillo, México. Correo electrónico: rigo140479@yahoo.com.mx

\section{Gloria Ciria Valdéz, Gardea}

Doctora en Antropología Cultural, University of Arizona.Profesor-investigador en el Colegio de Sonora, Hermosillo, México.Correo electrónico: gvaldez@colson.edu.mx 


\title{
"Crisis humanitaria": El rol de las redes sociales en el proceso migratorio de adolescentes migrantes
}

\section{Resumen}

Este artículo ofrece una alternativa teórica y metodológica para dimensionar el alcance de las redes sociales y así conocer la influencia, inversión y distancia recorrida que hace un adolescente en el municipio de Acambay, Estado de México, para obtener ayuda en un viaje migratorio hacia la frontera norte de México. Dimensionar el potencial de las redes sociales implicaría advertir un resultado negativo al reproducir información poco confiable. Tal es el caso de la "crisis humanitaria" de adolescentes migrantes que realizan el viaje migratorio con la falsa esperanza de recibir asilo político en Estados Unidos. Para analizar la morfología de una red, se utiliza el Software especializado UCINET6.
Palabras clave: Redes sociales, morfología de la red, adolescentes, Acambay, UCINET6, migración.

\section{"Humanitarian crisis": The Role of Social Networks in the Migratory Process of Adolescent Migrants}

\begin{abstract}
This article offers a theoretical and methodological alternative to gauge the extent of social networks to determine the influence, investment and distance that makes a child or teenager in the town of Acambay, State of Mexico for help on a migratory journey to the northern border of Mexico. Sizing the potential of networks would notice a negative result when playing unreliable information. Such is the case of the "humanitarian crisis" of migrant children who perform the migration journey with the false hope of receiving political asylum in the United States. To analyze information from a network specialist Software UCINET6 used.
\end{abstract}

Keywords: Social networks, network morphology, adolescents, Acambay, UCINET6, migration. 
Las migraciones humanas son muy antiguas, tenerlo presente es sin duda saludable. Sobre todo, si se piensa en posibles contribuciones de política pública que atiendan al fenómeno migratorio a nivel internacional. A lo largo del tiempo, las migraciones humanas se han ido adaptando y evolucionando de acuerdo con las causas que las motivan, lo que representan desde el punto de vista político, social, económico y cultural, los actores que participan y las consecuencias que tienen tanto en el lugar de origen como de destino.

Las investigaciones que han trabajado el tema de la migración y el papel que tienen las redes sociales de migrantes, no migrantes y futuros migrantes son vastas: Bolíbar (2011), Carnet (2011), Mummert (2009), Pérez y Rebolledo (2009), Díaz (2009), Valdéz-Gardea (2008a, 2008b y 2011), Herrera-Lima et al. (2007), Villaseñor y Moreno-Mena (2006), De Miguel (2006), Arango (2005), López-Castro (2005), Gallo-Kampos (2005), Pérez-Monterosas (2003), Goycochea y Ramírez (2002); por mencionar algunos ejemplos.

La mayoría de las investigaciones han enfocado su atención en una de las principales funciones de las redes sociales en el proceso migratorio: conectar a los individuos desde el lugar de origen con el lugar de destino.

En su momento, Lomnitz (1989) pudo identificar un patrón de conducta reiterativo que se puede traducir en: La Funcionalidad Instrumental de las Redes Sociales (Abello y Madariaga, 1998). El fin del presente trabajo, a diferencia de los autores antes citados; radica en ofrecer una herramienta metodológica para dimensionar esa función instrumental que contienen las redes sociales, en un contexto migratorio donde el actor principal de este

\section{Introducción}


artículo encierra tres situaciones de vulnerabilidad: ser menor de 18 años cumplidos, ser migrante y viajar solo.

Las redes sociales, en el proceso migratorio, son una de las principales causas por las que las migraciones internacionales han perdurado en el tiempo, también son las responsables de que el fenómeno migratorio evolucione y se adapte al contexto contemporáneo: "[las redes] son un conjunto de vínculos interpersonales que conectan a migrantes, antiguos migrantes y no migrantes en su área de origen y de destino a través de lazos de parentesco, amistad y comunidad de origen compartida" (Massey et al., 1998, p. 448).

Son precisamente los vínculos existentes en las redes sociales los que se encargan de reproducir las experiencias exitosas de un viaje migratorio. Se trata de un mecanismo social mediante el cual se canaliza la información y se minimizan los riesgos inherentes a toda aventura migratoria.

El presente documento analiza las redes sociales de adolescentes en el municipio de Acambay, Estado de México, México. El trabajo tiene su base en la propuesta teórica y metodológica conocida como Análisis de Redes Sociales (ARS). Dicha propuesta pone los acentos en la morfología de las redes sociales, en la posición o lugar que tiene un actor dentro de la red al momento de activarlas y en la función instrumental que contiene toda red social.

El principal interés es establecer una propuesta metodológica para los estudios de la migración, particularmente la migración de adolescentes. Lo anterior tiene importancia porque se considera que uno de los grupos 
sociales más vulnerables en un contexto migratorio son precisamente los niños, niñas y adolescentes.

En este artículo se considera a la red social como una institución estructural que observa lazos que unen actores y que están fundados en datos empíricos sistemáticos, altamente ligados con la graficación de imágenes y sustentados en el uso de modelos computacionales. Así pues, se utilizará un software especializado conocido como UCINET6 ${ }^{1}$, para analizar dichas redes sociales.

Así las cosas, en el primer apartado se expone lo que se entiende por adolescente y por red social; asimismo, la relación que existe con el fenómeno migratorio. En el segundo apartado se describe la propuesta teórica y metodológica del ARS, su elemento objetivo y cognitivo de interacción y hecho social. En este mismo apartado se establecen las características morfológicas de una red, como los atributos particulares que adquieren los actores al momento de activar sus redes para determinar la posición que tienen dentro de esta. En el tercer apartado se presenta el software especializado en redes sociales UCINET6 como herramienta base del ARS para explicar las estadísticas descriptivas de una red. En el cuarto apartado se explica la metodología para recabar la información y los resultados de la investigación de campo que se llevó a cabo en el municipio de Acambay, Estado de México. 
Lo que se entenderá por adolescente parte, en principio, de la definición establecida en un tratado de la Organización de las Naciones Unidas, durante la Convención Sobre los Derechos del Niño, la cual inició en 1978 y culminó el 20 de noviembre de 1989. En 1990, dicho acuerdo dio como resultado una Ley que firmaron veinte países. Actualmente es aceptada por todos los países, excepto Somalia y Estados Unidos.

El Artículo 1 expone la definición de niño: “todas las personas menores de 18 años, salvo que en virtud de la ley que le sea aplicable, haya alcanzado antes la mayoría de edad". De manera complementaria y de acuerdo con la Organización Mundial de la Salud (OMS); "La adolescencia es la etapa entre los 10 y 19 años, considerándose dos fases: la adolescencia temprana (10 a 14 años) y la adolescencia tardía (15 a 19 años)" (Pineda \& Aliño, 2009, p. 16). El interés por definir una particular fase o etapa de la vida humana está ligado a los cambios políticos, económicos, culturales, al desarrollo industrial y educacional, también al papel que comienzan a jugar los jóvenes en la actualidad.

En las últimas generaciones se manifiesta la aparición cada vez más temprana de la maduración sexual y la participación activa de los jóvenes en la esfera social, política, cultural y económica, por lo que representa un desafío importante para los países (...) (Pineda \& Aliño, 2009, p. 15).

Por lo anterior se entenderá como adolescente a todo aquel individuo entre los 15-17 años cumplidos (adolescencia tardía). Se toma esta decisión a partir de algunas características intrínsecas de la propia definición: aspectos psicosociales, como la búsqueda de sí mismos y la independencia como actitud identitaria; la tendencia grupal; la evolución del pensamiento, de lo concreto a lo abstracto; la necesidad intelectual; las manifestaciones

\section{Adolescentes $y$ red social}

\author{
Adolescente
}


y conductas sexuales; la elección de una ocupación y la necesidad de adiestramiento; la capacitación para su desempeño; y la necesidad de formulación y respuesta para su proyecto de vida (Pineda \& Aliño, 2009). Se considera de suma importancia acotar que las características antes citadas otorgan elementos sustanciales para considerar a los adolescentes como actores sociales y sujetos históricos con su propio capital cultural, social, simbólico y económico. Lo anterior es utilizado para transformar su propio entorno, a partir de experiencias individuales.

Massey, et al. (1998) menciona que una primera definición de redes o cadenas en el proceso migratorio es:

"Migrant networks are sets of interpersonal ties that connect migrants, former migrants, and nonmigrants in origin and destination areas through ties of kinship, friendship, and shared community origin". [Un conjunto de vínculos interpersonales que conectan a migrantes, antiguos migrantes y no migrantes en su área de origen y de destino a través de los lazos de parentesco, amistad y comunidad de origen compartida] (Massey et al., 1998, p. 448).

Se trata de un mecanismo social mediante el cual se canaliza la información y se minimizan los riesgos inherentes a toda aventura migratoria.

El concepto contiene, siguiendo a Massey, una ventaja analítica que permite integrar las características individuales, el parentesco y el conjunto de relaciones sociales como factores explicativos de los procesos migratorios en los lugares de origen y de destino. Una parte fundamental para abordar el fenómeno migratorio desde las redes sociales es considerar el contexto individual y social que rodea a un individuo que experimenta 
una movilización en busca de "algo mejor". Sobre todo, se debe centrar la atención en las relaciones sociales de aquellos que ya han experimentado el proceso migratorio (experiencias exitosas y no exitosas) y en los vínculos de los adolescentes que hayan experimentado el viaje migratorio o que se encuentren viviendo en Estados Unidos.

Streeter y Gillespie (1992) definen a una red social como "cualquier conjunto limitado de entidades sociales conectadas" (p. 202). Knoke y Yang (2008) establecen que "una red social es una estructura compuesta por un conjunto de actores, donde algunos de ellos están conectados por una o más relaciones" (p. 8). En el mismo entendido, Wasserman y Faust (1999) explican que una red social es "un conjunto finito de actores y la relación o relaciones que los vinculan" (p. 21). ${ }^{2}$

En términos analíticos, Aguirre (2011) propone que una red social "está compuesta por un conjunto finito de actores y configurada en torno a una serie de relaciones entre ellos, que se puede representar en forma de uno o varios grafos. Los grafos se componen de nodos que representan actores, y aristas que representan las relaciones entre ellos" (p. 15). En un sentido estricto, este autor especifica que una red social también contiene un criterio de límite; "se determina la pertenencia -o membrecía- de un actor de la red (...) el criterio por el cual definimos un conjunto particular de actores (y no otros) que configuran una red" (p. 15).

En lo que se refiere a términos teóricos, "una red social puede configurar contextos de comunicación e intercambio, configura pautas operativas, normas y valores que condicionan la conducta de los actores en ellas, y posiciones funcionalmente diferenciables" (Aguirre, 2011, pp. 15-16). Elementos que, a decir del autor, son claves para entender el 
comportamiento de los actores dentro de cualquier red social. El comportamiento guarda relación directa con las relaciones y las posiciones estratégicas que se desarrollan dentro de una red. Se trata de posiciones estratégicas diferenciables; posiciones que contienen el comportamiento, la acción, su acceso y la influencia sobre los recursos y bienes que se distribuyen dentro de la red (Aguirre, 2011).

Una red social permite la vinculación de un individuo con otro de manera presencial, se trata de un conjunto de relaciones que mantienen las personas y los grupos entre sí. En este sentido, lo relevante de una red social es el nivel meso-sociológico; propuesta analítica que tiene sus bases en George Simmel (Giner, 2014).

Lo que Giner (2014) retoma de Simmel es la idea de que para poder analizar a una sociedad en constante cambio es necesario abordarla desde dos visiones: formalista y dualista. La primera se centra en la forma de las interacciones sociales y trata de estudiarlas para comprender la emergencia, el mantenimiento, lo que está en juego y las transformaciones de las formas sociales. Esta visión formalista prefiere saber si una interacción es recíproca e igualitaria en lugar de determinar si se trata de una relación de amor o de amistad.

El enfoque simmeliano se presenta como un dualismo metodológico porque las formas sociales son engendradas por las interacciones entre los individuos, por un lado, y la percepción antagónica entre holismo e individualismo, por el otro. De ahí la importancia de aportar una definición de red social que se enfoque a la posible transformación de las estructuras 
sociales desde las interacciones sociales. Lo anterior sabiendo que las interacciones individuales deben servir de método interpretativo de lo social; por ejemplo, la posibilidad de interpretar el proceso migratorio a partir de las relaciones que se reproducen en las redes sociales de los actores migrantes. Así pues, considerando el proceso migratorio como una estructura social que está construyéndose o en proceso de construcción, la red social se convierte en una meta y no en un medio.

Para Barry-Wellman (2000), cualquier investigación que trabaje el concepto de red social, sin importar el contexto (proceso migratorio, por ejemplo), se tiene que materializar desde una visión estructural. El autor asegura que lejos del simplismo metodológico que pudiera pensarse con una propuesta como la visión estructural; se trata de una forma comprehensiva y paradigmática de considerar la estructura social de una manera seria, a partir del estudio directo de la forma en que los patrones de vinculación asignan los recursos de un sistema social. Lo anterior tiene justificación si se considera que:

El comportamiento es interpretado en términos de restricciones estructurales sobre la actividad, antes que en términos de fuerzas internas existentes dentro de las unidades (socialización en vez de normas), las cuales impulsan el comportamiento con un ímpetu voluntarista, a veces teleológico, hacia una meta deseada. El análisis [de redes] se centra en las relaciones entre unidades, y no en la clasificación de las unidades en categorías definidas por atributos internos (o esencias) de dichas unidades (Wellman, 2000, p. 12).

A partir de la propuesta de análisis estructural, Wellman define a una red social como un "conjunto de lazos que vinculan a los miembros del sistema 
social a través, y más allá, de las categorías sociales y los grupos cerrados" (p. 13). Esta definición se centra en el análisis de las relaciones entre unidades y no en los atributos internos de las unidades. No se trata de analizar el sexo, raza, edad, clase social, espacio geográfico o el nivel de estudios que contienen las unidades; sino de analizar las relaciones entre las unidades y examinar de qué manera estas relaciones modifican una estructura social o influyen en las decisiones que se toman dentro de una red o estructura. Aún más importante, considerar cómo las interacciones se modifican a partir de la morfología de una red social.

En cuanto a las características centrales de una red social, Aguirre (2011) centra su atención en tres elementos: actores, relaciones entre ellos y los límites de la red. Los actores se definen como nodos representados en un grafo; pueden ser individuos, grupos o instituciones. Las relaciones no se toman como una cualidad de los actores; sino como "una propiedad diádica que existe en tanto ambos actores mantenga su asociación" (Knoke \& Yang, 2008, citados por Aguirre, 2011, p. 22). Los límites de la red son el criterio que determina la pertenencia o membrecía de los actores de la red; denota el cierre social de esa red: "El límite de la red debe guardar una estrecha relación lógica con la relación que constituye esa red, ya que es el tipo de relación el que determina qué sujetos participan de ella" (Aguirre, 2001, p. 25).

La propuesta metodológica, desde la que se define una red social, podría rastrear flujos de información horizontal y vertical, identificar fuentes y objetivos y determinar la existencia de restricciones estructurales que inciden sobre los flujos de información. También aporta una dimensión real del alcance que tienen las redes sociales y de la importancia que es 
considerar a la red social como una de las herramientas fundamentales para informar o desinformar. Todo depende de la forma y de las características de la red social que se activa al momento en que un adolescente solicite apoyo para un viaje migratorio.

En el proceso migratorio de adolescentes, las relaciones se manifestarían en forma de lazos entre los actores o nodos (vínculos o relaciones entre los actores). En este sentido, las redes en el proceso migratorio son el conjunto de lazos entre nodos.

De las definiciones expuestas sobre el concepto de redes sociales, queda claro que la función inmediata que las redes contienen está relacionada con "un conjunto de asociaciones recurrentes entre grupos de personas ligadas por lazos ocupacionales, familiares, culturales o afectivos. Llegan a ser tan importantes en la medida que son medios para la adquisición de recursos tan escasos como el capital y la información" (Portes, 1999; citado por Díaz, 2009, p. 10). Si se considera que la migración internacional es una constante construcción de redes sociales y que no solo se trata de movilizaciones espaciales; la red juega un papel fundamental, ya que por cada persona que se convierte en migrante, se reduce el costo de la migración para aquello que irán después.

Para fines de este documento, y después de haber presentado varias definiciones del concepto de red social, se entenderá por red social lo ya establecido por Massey, et al. (1998), que parte de la esencia descrita por Abello et al. (2003), en cuanto a interacción cara a cara: 
Conjunto de vínculos interpersonales que conectan a migrantes, antiguos migrantes y no migrantes en su área de origen y de destino a través de los lazos de parentesco, amistad y comunidad de origen compartida" (Massey et al., 1998, p. 448).

El hecho de tomar como definición principal lo expuesto por Massey radica en que dicha definición contiene algunos aspectos no considerados en otros planteamientos expuestos anteriormente, a saber:

1. La familia expresada a través de vínculos de parentesco.

2. La dimensión, local materializada en las relaciones amistad y de paisanaje.

3. La interconexión que se produce entre las áreas de origen y destino, los migrantes de diferentes periodos y aquellos que aún no han realizado ninguna migración, pero que pueden ser potenciales migrantes (Massey et al., 1998).

Parte sustancial es analizar las redes sociales de adolescentes en el proceso migratorio y particularmente las interrelaciones que se reproducen en un contexto migratorio. Como primer elemento para el análisis, se tiene ya una definición de red social. El siguiente apartado da cuenta del Análisis de Redes Sociales como propuesta teórica y metodológica para abordar las interrelaciones que se reproducen en una red social. 
El Análisis de Redes Sociales (ARS) surge como una aproximación teórica y metodológica que permite analizar la composición y dinámica de una red (morfología), la centralidad de los actores, el agrupamiento y sistemas de cohesión internos y los papeles sociales diferenciados (atributos a partir de la activación de las redes sociales) (Rodríguez, 2004).

El principal interés que incentiva la propuesta teórica y metodológica del ARS radica en considerar a los fenómenos sociales como relaciones entre sujetos o entidades sociales, donde lo social no se constituye, en primera instancia, mediante categorías sociales o atributos de los individuos (sexo, raza, edad, condición social, etc.), sino por los vínculos entre actores, incluso no estando directamente relacionados.

El ARS considera que en el origen de todo fenómeno social se encuentra la interacción social y su correlato inmediato: el hecho social. Ambos son considerados como "una entidad dual, ontológica y socialmente inseparable" (Lozares, 2005, p. 10). Esta dualidad ontológica es el núcleo primigenio de lo social, por tanto, su unidad de referencia más elemental. En palabras de Lozares (2005), “es como un conjunto de prácticas objetivas y cognitivas de intercambio, interacciones sociales, entre agentes, personas y/o artefactos, que ponen en juego sus recursos con la intención o propósito, manifiesto o no, de captar y/o apropiarse del producto emergente, hecho social, que se genera en el propio desarrollo de la interacción" (pp. 10-11).

\section{Análisis de Redes Sociales (ARS)}


Tabla 1

Interacción y hecho social como dualidad ontológica en el proceso migratorio de los adolescentes

1. Interacción: Agentes marcados como prestador de servicios fronterizos (pollero, coyote, burrero, entre otros nombres) y el usuario de estos servicios (migrante o algún miembro de la red social que vincula directamente al posible migrante) y otros agentes en espera de contratar el servicio (otros migrantes con experiencia exitosa que se encuentran viviendo en Estados Unidos).

2. Hecho social: Todos los agentes contienen recursos propios (económicos, por ejemplo) que definen al mismo usuario de los servicios, por ende, al prestador de servicios.

3. Interacción y hecho social: Observamos prácticas de intercambio con dos canales: subjetivo (intercambios emocionales, de cortesía, amistad, recuerdos, experiencias, etcétera) y cognitivo (intercambio de información a partir de conversación gestual o corporal y manual y a partir de "recomendaciones" exitosas al momento de cruzar la línea fronteriza).

4. Interacción: La interacción lleva su propio curso de desarrollo: entrada o presentación, saludo, intercambio de información, alternativas, propuesta, oferta, contraoferta, elección, cierre del trato y posible desenlace.

5. Hecho social: Al tratarse de una actividad considerada como de alto riesgo; es la misma red social la que fortalece el trato o el acuerdo ya que se cuenta con experiencias previas (exitosas en cuanto al cruce fronterizo).

6. Hecho social: Primero se desarrolla en un campo familiar, gremial, de amistad o vecinaje para dar paso a otro campo socio económico donde existe oferta y demanda (una especia de mercado migratorio donde se ofertan servicios para cruzar la frontera $\sin$ los documentos expeditos por la autoridad migratoria).
Los actores pretenden modificar su realidad a partir de este tipo de interacción.

Los recursos definen a los agentes.

Dualidad inseparable con una carga de subjetivación y otra carga cognitiva. Lo trascendente es que esta dualidad está presente en todos los agentes que intervienen durante todo el proceso migratorio de los adolescentes.

Modificación permanente de la acción. No se obtienen los resultados esperados puesto que se está en un dinamismo que constantemente modifica los resultados que se habían previsto.

Se reproduce una apropiación del posible desenlace negativo; hecho que está como posibilidad desde el inicio de la interacción.

Campos o elementos del hecho social qu constriñen la interacción: oferta y demanc de los servicios.

Nota: Los campos y contextos son los lugares de origen y destino, y la condición socio-cultural de quien utiliza los servicios. Elaboración propia, a partir de Lozares, 2005. 
El ARS parte de la noción primaria de red como sistema de vínculos y ligas entre nodos o entidades sociales, y parte de los vínculos como estructuras de comunicación interpersonal, aunque actualmente se considera que los nodos pueden ser agregados (por ejemplo, organizaciones o países) o pueden ser posiciones. Si bien se supone que las estructuras de las relaciones sociales tienen un poder explicativo mayor que los atributos de los miembros que componen un sistema dado, cualquier tipo de relación social puede ser tratada como red (Luna, 2004, p. 61-62).

El ARS centra su atención en las interacciones y hechos sociales; dualidad ontológica inseparable y presente en las redes sociales del proceso migratorio. La tendencia del enfoque del ARS está en concebir que el mundo entero está constituido por redes y no por grupos donde las normas sociales no responden a las características de los individuos, sino a su posición dentro de las redes. Esta tendencia generaliza y expone, desde este punto de vista, una debilidad: las redes sociales están constituidas por grupos y, sobre todo, por individuos con características individuales que pudieran interpretarse como elementos contextuales que marcarían diferencia.

Si bien las normas establecidas en una estructura social, como el proceso migratorio de los adolescentes, pueden determinar la posición que se ocupe dentro de una red; las características particulares del individuo juegan un papel trascendente porque el individuo es un actor histórico-cultural y sujeto social que depende de estas características para ocupar un lugar dentro de una red. Sin embargo, el ARS solo se enfoca en las relaciones entre entidades sociales y no en los atributos individuales. 
¿Exactamente qué estudia el ARS? En principio, se enfoca a medir los grados de centralidad y densidad (relación entre los lazos existentes y los lazos posibles) de una red y particularmente la morfología de una red que distingue dos tipos de redes: homófilas y heterófilas. A decir de Lozares y Miquel (2011):

La Homofilia se refiere al hecho social de que se den con mayor probabilidad prácticas, hábitos, opiniones, conocimientos mutuos y relaciones comunes entre individuos con características sociales iguales como edad, género, nivel educativo, ocupación, clase social, etc. que entre diferentes atributos. Esto es, que pares de individuos equivalentes en sus atributos sociales tienen más posibilidad de tener mayor frecuencia en sus encuentros, más concordancia en sus opiniones o prácticas similares que si no se da de tal equivalencia. La mayor probabilidad de tales actividades o concordancias con los no similares o no equivalentes sería la Heterofília (p. 30).

Parte sustancial del estudio del ARS es el hecho de reconocer en las redes una personalidad homofílica o heterofílica. Lo trascendente de estas dos personalidades es que existen criterios de clasificación que incrementan la personalidad de las redes sociales y es en este punto donde el ARS pone el acento. A saber, un primer criterio de clasificación consiste en la distinción entre homofilia individual y estructural: "La homofilia individual se manifiesta o explica a partir de preferencias individuales. En el criterio estructural las relaciones homofílicas están constreñidas por características, contextos o situaciones externas a los individuos; algunos ejemplos son la localización geográfica, ocupación, lugar de trabajo, etc." (Lozares \& Miquel, 2011, p. 30). 
Los criterios antes mencionados contienen un valor y estatus homofílico, y corresponden a la idea que es más útil interactuar con los que mantienen valores similares que con los que no, sobre todo porque interviene una razón instrumental de utilidades.

Además de la centralidad, densidad y el carácter homofílico o heterofílico de las redes sociales, el ARS se enfoca en elementos particulares de la morfología de una red. El análisis morfológico contiene elementos que ayudarán a entender cómo se distribuyen los bienes que contiene una red y cómo están dispuestos los actores dentro de una red, el alcance y sus límites. Adicionalmente, la morfología proporciona atributos particulares a los actores que activan o hacen uso de la red social. Se trata de atributos a posteriori; es decir, atributos que adquieren los actores después de hacer uso de la red social y una vez que se desarrollan las interrelaciones entre los actores de las redes y que emergen como estadísticas descriptivas de la red.

El ARS parte de dos estudios para determinar la distribución de los bienes en una red; el primero es el análisis de redes totales: el investigador se posiciona por fuera del universo estudiado y estudia los lazos de todos los integrantes del universo seleccionado. ${ }^{3}$ El segundo estudio se centra en el análisis de redes egocéntricas: se plantea la red desde el punto de vista del individuo que se posiciona como ego (en el centro). Este último tipo de estudios se ha centrado en los temas de integración social y plantea que las cuestiones de acceso a recursos están estrechamente ligadas a las formas de las redes. Sostiene que el comportamiento social se analiza mejor estudiando cómo las redes asignan sus recursos a los miembros (Luna, 2004). Se trata de un análisis de las estadísticas descriptivas de cada red y de cada actor que participa en la red. 
Tomando en cuenta que lo central en el ARS son las relaciones entre actores; es de suma importancia considerar la posición y el rol que juegan los participantes dentro de una red social para poder entender, por ejemplo:

a) Las relaciones de intercambio: Recurso e información, la red tiene como principal funcionalidad el intercambio de recursos porque se espera satisfacer alguna necesidad. Se participa porque se busca beneficio (negociación).

b) También para entender la adquisición de posiciones sociales: El poder juega un papel básico porque hace la diferencia entre individuos de una red. La fuente de poder reside en las relaciones sociales (se tiene más acceso a ciertos recursos). Asimismo, el poder es considerado como formal (autoridad), poder técnico (conocimiento) y poder informal (centralidad de la persona en la red).

c) La influencia social: Se describe a partir de la imitación, la enseñanza, la persuasión y el contagio. Una de las características fundamentales es que la norma de conducta que sirve de comparación depende de la red social. El individuo se compara con esa norma y ajusta el comportamiento.

Es así como el ARS se enfoca a la morfología de una red y en los atributos que adquiere el actor cuando hace uso de la red; se apoya de herramientas matemáticas y computacionales para hacerlo.

Las propiedades de las redes que se analizaron y que forman parte de la morfología son: 
Tabla 2

Propiedades de una red que serán analizadas (estadísticas descriptivas de una red) Elemento de Descripción y función análisis

$\begin{array}{lll}\begin{array}{l}\text { Tipo } \\ \text { relaciones }\end{array} & \text { Los actores son escogidos por los pares que él selecciona. } \\ & \text { Asimétricas } & \begin{array}{l}\text { Los actores no son necesariamente escogidos por aquellos que ellos } \\ \text { seleccionan. }\end{array}\end{array}$

Densidad La densidad mide la proporción de relaciones existentes sobre el total de las relaciones posibles. Indica la intensidad de las relaciones en el conjunto de la red.

Centralidad Estudia a los actores más centrales, más prominentes, con más poder de influencia y prestigiosos. En las relaciones asimétricas se reconocen los indicadores: outdegree e indegree. En las relaciones simétricas el indicador es grado (se asumen las relaciones directas que tiene cada actor).

Grado (degree): Outdegree: Inicio de contacto, indica el número de conexiones o relaciones directas iniciadas por cada actor. Refleja la actividad social de cada actor como su capacidad para acceder al resto de actores.

Indegree: Recepción de relaciones, indica el número de actores que se relacionan de forma directa a cada actor (las veces que es elegido por los demás actores). Permite conocer a los actores más prestigiosos o de referencia para el resto de la red. Indicador que mide el prestigio y poder.

Cercanía La cercanía mide la distancia media de cada actor con respecto al resto de actores de la red. Los indicadores mayores sugieren que hay una facilidad mayor de acceso al resto de los miembros de la red. Una mayor capacidad de obtener y enviar información.

Intermediación Nos indica para cada actor en qué medida está en una posición intermediaria (vínculos débiles o puentes) en las comunicaciones geodésicas entre el resto de actores. Los actores con mayor intermediación tienen un gran poder porque controlan los flujos de comunicación.

Nota: Elaboración propia, a partir de Velázquez y Aguilar, 2005. 
"UCINET6 posee una plataforma para el manejo de datos y herramientas de transformación para realizar procedimientos de teoremas gráficos con un lenguaje algebraico interpuesto por matrices" (Velázquez \& Aguilar, 2005, p. 44). Al utilizar el software especializado en redes sociales; la metodología se basa en el diseño de matrices para una codificación binaria que es el lenguaje que permite el dicho software.

Para recabar la información en el Estado de México, se diseñó una matriz que permite identificar las redes sociales de adolescentes, con la intención de comprobar la existencia de vínculos interpersonales que pudieran conectar a los integrantes de una red con algún familiar o conocido que haya realizado el viaje migratorio (interrelaciones entre no migrantes y migrantes). Se construyó una secuencia lógica de diez matrices que demostraron y reafirmaron los diferentes niveles de confianza, reciprocidad y acceso a la información migratoria (presencia de vínculos internacionales). Adicionalmente, las matrices diseñadas arrojan los atributos que cada actor adquiere al momento de activar su red social. La base metodológica parte del principio de sociogramas, donde la elección de sus compañeros se realiza a partir de un rol funcional dentro de la red. Se obtuvieron dos matrices para el análisis de dos posibles redes sociales.

1. Matriz de homofilia: Red Homofílica, "prácticas, hábitos, opiniones, conocimientos mutuos y relaciones comunes entre individuos con características sociales iguales como: edad, género, nivel educativo, ocupación, clase social, etcétera" (Lozares \& Verd, 2011, p. 30).

\section{Metodología para \\ el Análisis de \\ Redes Sociales: \\ UCINET6}


2. Matriz de información migratoria (presencia de vínculos internacionales): Red de información migratoria; la esencia de las redes sociales parte del supuesto que se genera un intercambio mutuo, continuo, que constituye un sistema amplio de derechos y obligaciones dentro del grupo. La información migratoria responde a la funcionalidad instrumental de las rede sociales: "La ayuda instrumental hace referencia a aspectos como proporcionar dinero, cosas agradables, servicios varios e información necesaria" (Abello \& Madariaga, 1998, p. 122). Se trata de comprobar la presencia de vínculos internacionales: familiares, amigos, conocidos o vecinos que se encuentren viviendo en Estados Unidos -se considera un viaje migratorio exitoso-.

Lo que se pretende es analizar las características morfológicas de las redes identificadas en el municipio, a partir de los principios morfológicos que contienen las redes en un contexto migratorio. Lo anterior para determinar la posición estratégica de los actores que intervienen, así como el nivel de confianza en los actores. Confianza en el sentido de la posibilidad de interrelacionarse con los vínculos internacionales.

Acambay, Estado de México, es uno de los municipios del Estado con menor participación migratoria por parte de sus habitantes. De acuerdo con el Instituto Nacional de Estadística y Geografía de México (INEGI), tan solo 971 personas nacidas en dicho municipio viven en los Estados Unidos. ${ }^{4}$ Resultó de suma importancia enfocar el trabajo de campo en las comunidades con mayor presencia migratoria de todo el Municipio.

\section{Las redes sociales en el Estado de México}


Así las cosas, las comunidades donde se llevó a cabo el trabajo de campo son: Juandó, San Francisco Xhasni, La Loma y Agostadero. Comunidades que se encuentran en la parte noroeste del municipio. Se toma la decisión, a partir de las entrevistas con autoridades municipales y escolares, ya que son las mismas autoridades las que reconocen la parte noroeste del municipio como la de mayor presencia del fenómeno migratorio. Si bien el presente documento se enfoca en los adolescentes, resultaba un trabajo titánico encuestar a todos los adolescentes de las comunidades antes señaladas, de ahí que se decide concentrarse en un tipo de población que estuvieran "contenida" en un mismo espacio y contexto. En ese sentido, se toma la decisión de encuestar a adolescentes inscritos en las escuelas secundarias y preparatorias registradas en las diferentes comunidades, sobre todo porque los adolescentes inscritos oscilan entre 15-17 años cumplidos (adolescencia tardía).

Se tomaron en cuenta todas las escuelas secundarias y preparatorias de la zona: Escuela preparatoria No. 162, Juandó; Escuela Preparatoria No. 147, Agostadero; Escuela Secundaria Orozco Berra, San Francisco Xhasni; Escuela Secundaria Jorge Jiménez Cantú, Agostadero; Escuela Secundaria José María Morelos, La loma; y la Escuela Secundaria Ignacio Ramírez, San Francisco Xhasni, Acambay Estado de México.

Particularmente, en el municipio existe un alto potencial en cuanto a las redes sociales de cada individuo; son 971 individuos viviendo en EE.UU. que siguen manteniendo contacto mediante sus redes sociales. Las posibilidades de interaccionar se multiplican exponencialmente, lo que permite que un adolescente tenga acceso a la información migratoria. 
En 2010, 6.5 por ciento de los niños y adolescentes mexicanos (menores de 19 años) tenía alguna vinculación con la migración. Esto representa un total de 2.7 millones de menores. En su mayoría son menores residentes en viviendas en donde alguno de los habitantes había migrado a Estados Unidos o que recibían remesas (Giorguli \& Gutiérrez, 2011, p. 22).

Las relaciones que se grafican son de los adolescentes que se encontraban al momento de aplicar el cuestionario. En relación a si se tratan de relaciones asimétricas o simétricas; los hallazgos demuestran que no necesariamente el que elige será elegido por su par; por lo tanto, las relaciones que se reproducen en las comunidades del Municipio de Acambay, Estado de México, son asimétricas y están reducidas a un mismo espacio, tiempo y contexto, debido a que se aplicó la herramienta de investigación a los adolescentes entre 15-17 años cumplidos.

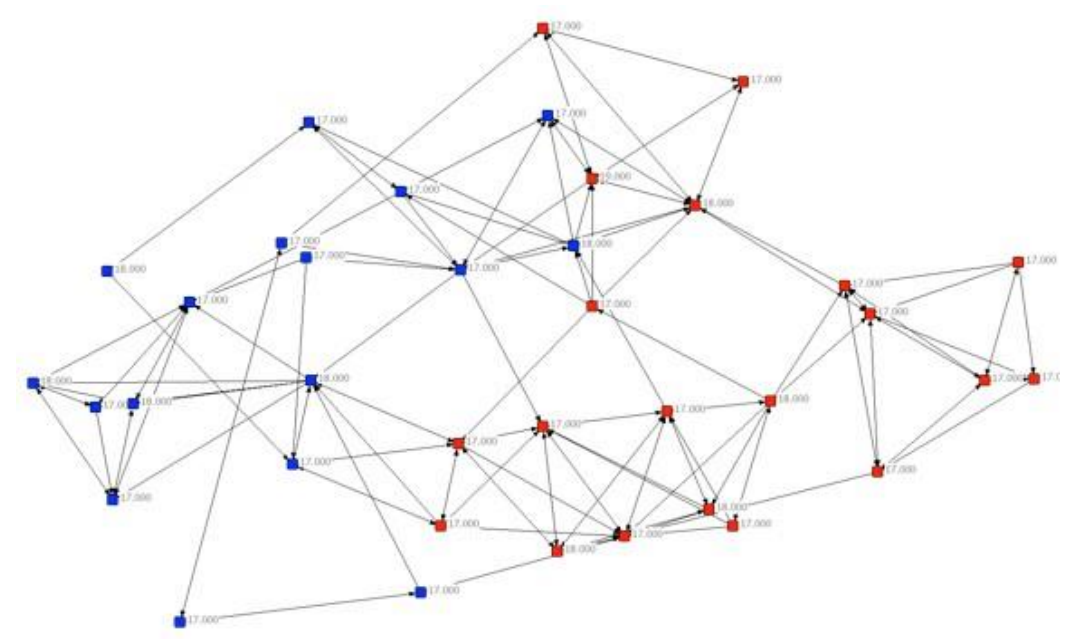

Figura 1. Red homofílica de la Preparatoria No. 147, comunidad Agostadero, Acambay.

Fuente: Elaboración propia.

\section{Redes homofílicas \\ en Acambay, \\ Estado de México}


"Crisis humanitaria": El rol de las redes sociales...

En principio, se generan relaciones asimétricas. En la Figura 1, se evidencia una red homofílica, en la cual se infiere que la distribución de los actores es a partir de la característica social de género y edad. La misma tendencia homofílica se identifica en el resto de las redes:

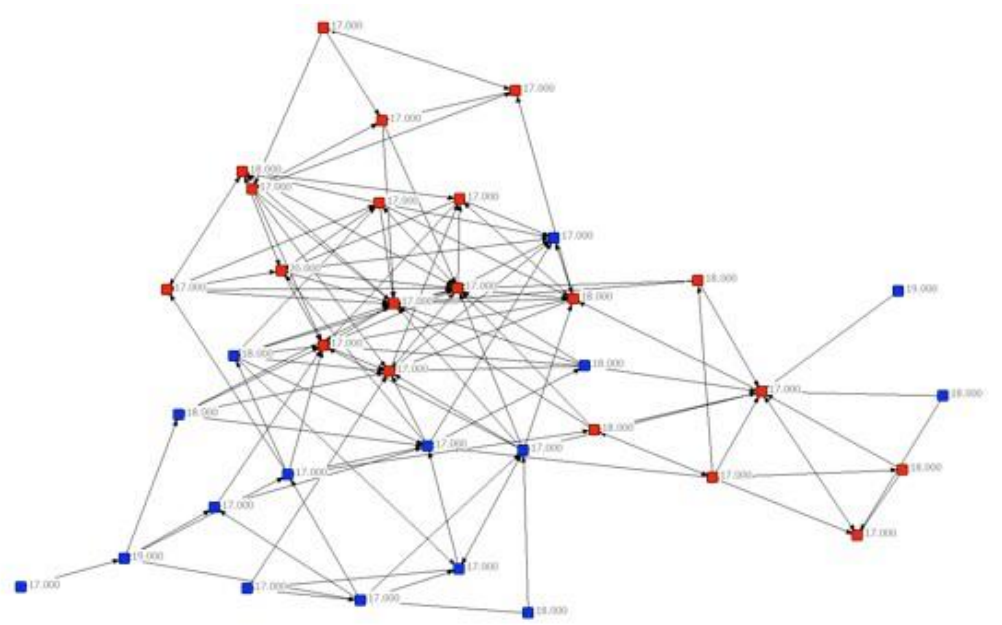

Figura 2. Red homofílica de la Preparatoria No. 162, comunidad de Juandó, Acambay.

Fuente: Elaboración propia. 


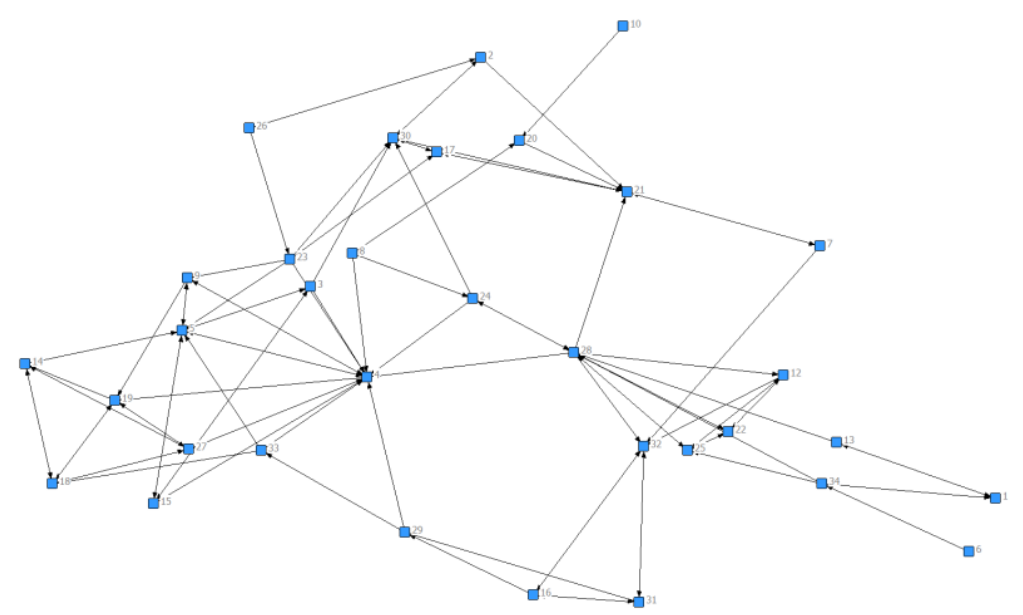

Figura 3. Red homofílica de la Secundaria Orozco Berra, San Francisco, Xhasni.

Fuente: Elaboración propia.

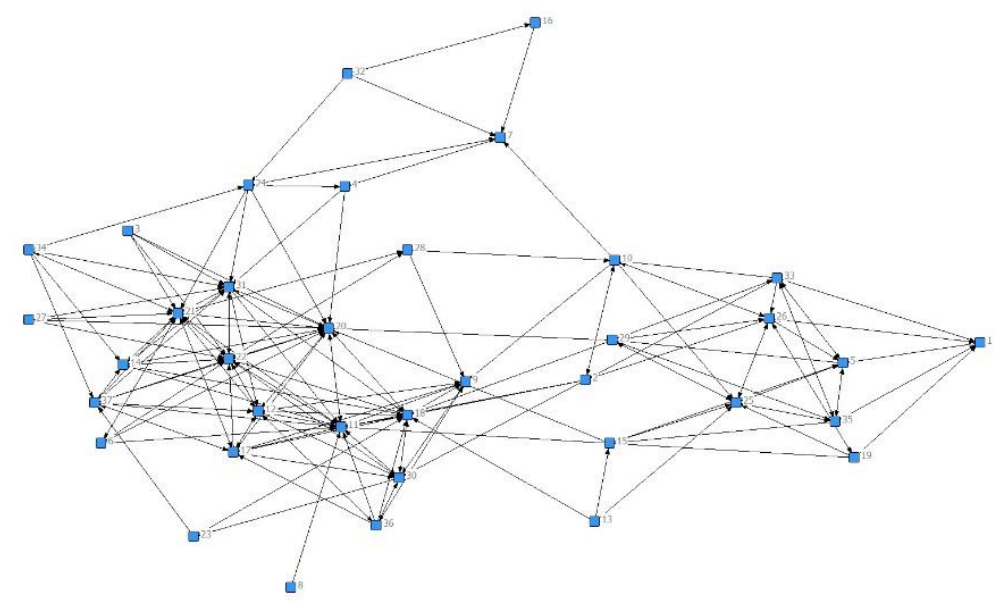

Figura 4. Red homofílica de la Secundaria Jorge Jiménez Cantú, Agostadero.

Fuente: Elaboración propia. 
"Crisis humanitaria": El rol de las redes sociales...

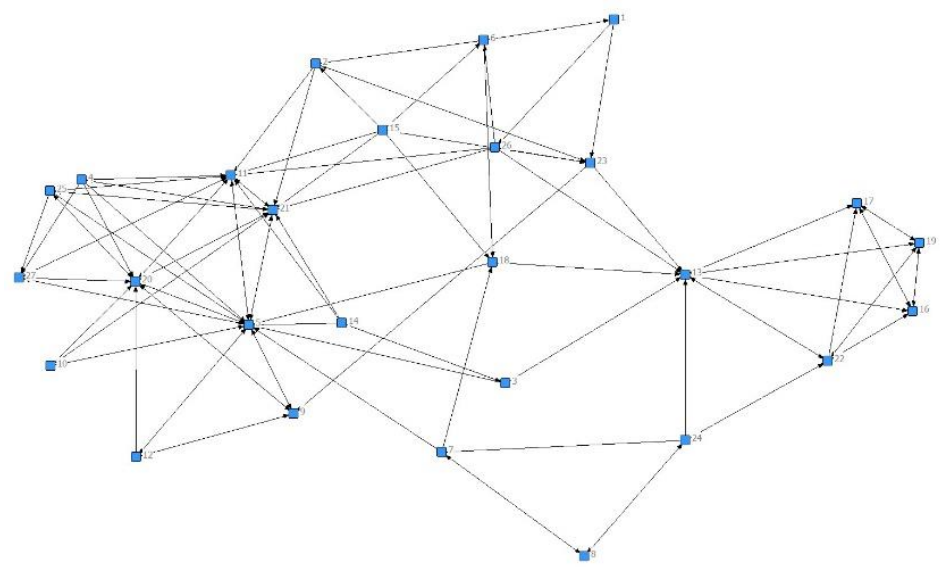

Figura 5. Red homofílica de la Secundaria Jorge Jiménez Cantú, Agostadero.

Fuente: Elaboración propia.

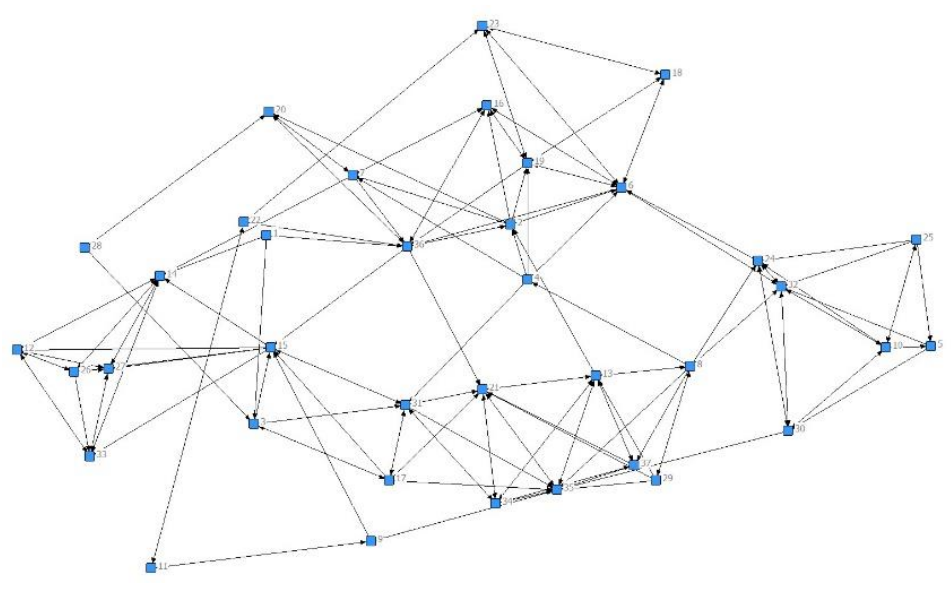

Figura 6. Red homofílica de la Secundaria Ignacio Ramírez, San Francisco, Xhasni.

Fuente: Elaboración propia. 
A partir de los mapas o redes identificadas en las figuras anteriores, se puede argumentar que las prácticas, hábitos, opiniones, conocimientos mutuos y las relaciones se generan entre individuos con características sociales iguales como el género, edad y nivel educativo. Los pares de actores son equivalentes en sus atributos sociales y les proporciona mayores posibilidades de frecuentarse o tener algún encuentro. Se trata de un proceso homofílico que presenta las siguientes fases: homofilia individual, homofilia de selección y homofilia inducida. Hecho que comprueba la presencia de redes sociales.

Al comprobar la existencia de redes sociales, es necesario comprobar el contexto migratorio que interesa en este trabajo. El contexto migratorio implica situar a los actores en la posibilidad de realizar un viaje migratorio hacia Estados Unidos y saber si tienen, a partir de activar las redes, la posibilidad de acceder a la información necesaria para el viaje. Lo anterior se llevó a cabo a partir de la definición de red social propuesta por Massey et al. (1998); al tratarse de vínculos interpersonales que conectan a migrantes, antiguos migrantes y no migrantes en su área de origen y de destino a través de lazos de parentesco, amistad y comunidad de origen, es necesario comprobar la presencia de esos vínculos con los adolescentes del municipio de Acambay.

Se trata de comprobar la presencia de los vínculos en territorio estadounidense. Al existir los lazos de parentesco, amistad o paisanaje en tierra extranjera, se parte del supuesto de que son estos vínculos los que contienen la información necesaria para que un adolescente realice un viaje migratorio, viaje que resultó para ellos en éxito debido a que actualmente se encuentran viviendo en Estados Unidos. No solo se trata de comprobar la existencia de los vínculos en el extranjero, sino también de comprobar 
que los adolescentes del municipio tienen acceso a esos vínculos como actores de la red ya comprobada y, de ser necesario, utilizarán esos lazos en el extranjero como ayuda al momento de realizar un viaje y reproducir la información en la red social de la que forman parte.

El nivel meso-sociológico de las redes sociales implica enfocar nuestra atención en las interrelaciones; cuando un actor identifica a sus pares como posibles vínculos de quienes se podría valer para solicitar ayuda, se estaría frente a una activación de la interacción y hecho social -dualidad ontológica inseparable-. El hecho de comprobar que los actores reconocen e identifican a sus compañeros que contienen esos vínculos en el extranjero da pie para argumentar que se están reproduciendo las prácticas objetivas y cognitivas de intercambio entre agentes, las cuales ponen en juego sus recursos con la intención de apropiarse de la información o de la posibilidad de interrelacionarse con los vínculos internacionales contenidos en la red. 


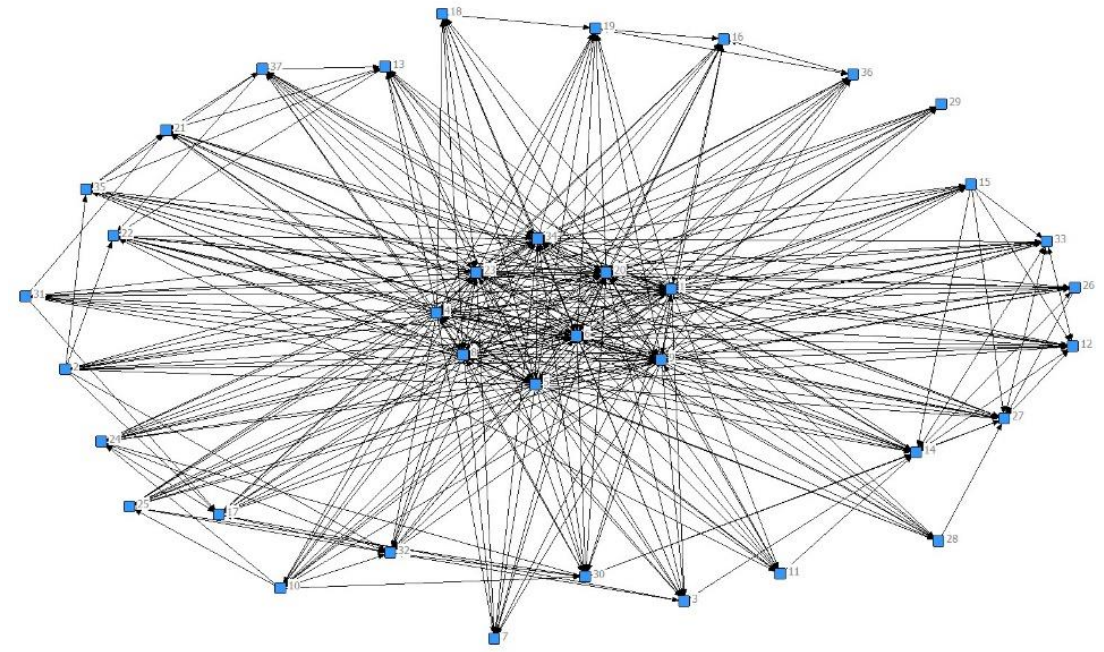

Figura 7. Red de información migratoria de la Preparatoria No. 147.

Fuente: Elaboración propia.

\section{Redes de} información migratoria en Acambay, Estado de México (presencia de vínculos internacionales)

A los adolescentes del municipio se les pidió que seleccionaran a los compañeros que tienen familia, amigos o algún conocido viviendo actualmente en Estados Unidos. Como se mencionó, se trata de comprobar la existencia de esos vínculos en el extranjero para determinar que existe la información migratoria en la red social.

La Figura 7 muestra la red de información migratoria en la preparatoria No. 147. Se trata de una imagen altamente conectada, donde los actores seleccionaron a los compañeros que tienen familia, amigos o algún conocido viviendo en Estados Unidos y que están representados con el número que los posiciona en una lista de asistencia. La gran mayoría de los 
actores sabe de alguien que tiene un vínculo en territorio extranjero; por lo tanto, todos los participantes tienen acceso a la información migratoria, si se presentara el caso.

Al momento de preparar un viaje -cualquiera que sea el motivo- cada individuo planea, con base en sus posibilidades, dicho viaje: ¿Cuánto dinero costará?, ¿dónde llegará?, ¿cuánto tiempo será necesario? Toda planeación significa ponderar entre la inversión que se tenga que hacer y los posibles resultados esperados. Durante un viaje migratorio sucede lo mismo; es necesario planear y ponderar entre inversión y posibles resultados. Se busca invertir lo menos posible, sobre todo porque se está frente a la incertidumbre de un futuro inmediato.

Así las cosas, acceder a la información implica una inversión que se tiene que considerar y es esta inversión lo que determina seleccionar la estrategia para el viaje. En principio se tiene que tomar en cuenta el hecho de obtener la información necesaria y valiosa para un viaje migratorio, que está contenida en su red social. Sin embargo, dentro de la misma red, las distancias que tiene que recorrer un actor para acceder a dicho bien o recurso está condicionada a la posición que dicho actor tiene dentro de su red.

El ARS se apoya en estadísticas descriptivas de las redes para establecer la posición de cada actor. Se trata de atributos a posteriori que cada actor tiene en una red social. Los atributos también determinan al actor o actores con mayor prestigio e influencia en la red; son aquellos actores que debido a su posición adquieren un reconocimiento social que implica una mayor confianza en el recurso que este actor pueda tener y también de una posible 
influencia en la totalidad de la red. Lo que estos actores digan, hagan o compartan, será poco cuestionado por los integrantes, puesto son ellos mismos los que reconocen la importancia social de sus compañeros.

Las estadísticas descriptivas de la red de información migratoria de la Preparatoria No. 147 ayudarán a comprobar, con mayor precisión, si la información realmente está al alcance de todos y también a identificar a los actores con mayor prestigio e influencia social. Asimismo, se podrá determinar, a partir de la posición que tenga el actor, si la inversión que hace para obtener información será significativamente menor o mayor a los resultados esperados. Teóricamente se trata de las estadísticas morfológicas de la red y de los actores contenidos en la red.

\section{Estadísticas}

descriptivas de la red de información migratoria (atributos de los actores) 


\section{Tabla 3}

Estadisticas descriptivas de la Red de Información Migratoria (Figura 7) de la Preparatoria No. 147

Atributo Red de Información Migratoria (presencia de vínculos internacionales)
1. Densidad
31.3 por ciento de 417 posibles relaciones
2. Grado medio
11.2 promedio de relaciones por actor
3. Centralidad
InDegree $^{5} 16.3$ por ciento la red depende de uno o varios actores.
OutDegree $^{6} 70.6$ por ciento la red depende de uno o varios actores.
4. Grado $\quad$ Actor 14: $17($ InDegree $)+4$ (OutDegree $)=$ Grado 21
Actor 13: 12 (InDegree) +7 (OutDegree $)=$ Grado19
Actor 30: 11 (InDegree $)+7$ (OutDegree $)=$ Grado 18
Actor 6:13 (InDegree $)+36($ OutDegree $)=$ Grado 49
5. Distancia geodésica 1 paso: 417 posibles relaciones
6. Cercanía 59 pasos el actor 14
7. Intermediación 152 distancias geodésicas que atraviesan por el actor
No. 6

Nota: Elaboración propia

El primer dato que nos arroja es la densidad de la red. Significa que de 417 posibles relaciones, únicamente se están produciendo el $31.3 \%$, de un total de 37 actores. Además, se trata de una red medianamente densa, lo que implica que la información que se reproduce no tiene un nivel de confianza alto. ${ }^{7}$ Sin embargo, el promedio de posibles relaciones de cada actor es de 11 , lo que significa que un actor tiene por lo menos diez compañeros a los 
que se podría acercar para interactuar y solicitar ayuda para vincularse con el familiar, amigo o conocido que tiene viviendo en Estados Unidos. Al tratarse de relaciones asimétricas, la influencia de un actor sobre la red es de $70.6 \%$; esto es, la dependencia o centralidad que la red tiene del actor seis está en la capacidad del actor de vincularse con la totalidad de sus compañeros. Por lo tanto, la influencia del actor seis se refleja en el porcentaje de OutDegree: se trata de la influencia de un actor sobre la red total.

Aunado a lo anterior, el actor con mayor prestigio social está representado con el $16.3 \%$ de centralidad o dependencia de la red; significa que el $16.3 \%$ de sus compañeros ven a un actor como aquel a quien realmente se acercarían, porque es él quien contiene la información necesaria y es reconocido por la mayoría de los actores. Se trata del actor 14: prestigio social a partir de ser reconocido por sus compañeros.

El grado de cada actor indica el número de compañeros que seleccionó y el número de selecciones que recibió (OutDegree+InDegree). Se trata del actor más importante de la red, porque tiene acceso a la totalidad de sus compañeros, y la mayoría de sus compañeros lo reconocen como tal. En este caso, se trata del actor seis con grado $49(36+13)$ y también el actor 14 con grado $21(4+17)$. Se identifica a los actores con mayor influencia y prestigio en la red; son quienes ostentan el mayor nivel de confianza debido al mismo reconocimiento social. 
La inversión que se tiene que hacer para legar a ellos o interrelacionarse con ellos es lo que se tiene que ponderar al momento de solicitar ayuda en un posible viaje migratorio. Se habla de inversión cuando se está frente a un intercambio recíproco de recursos que contienen los actores. En este punto, las distancias o pasos que un actor tiene que hacer para llegar a los actores 14 y 6 son considerados como inversión en cuanto a tiempo, capital económico y capital social.

El ARS arroja una estadística descriptiva que contabiliza los "pasos" que un actor puede dar hasta determinado protagonista. Distancias pueden existir varias, pero siempre se elige la distancia más corta, se denomina distancia geodésica. En la red de la Figura 7, las distancias geodésicas de 1 paso pueden conectar a 417 posibles relaciones; es decir, todas las posibles relaciones se pueden conectar mediante 1 paso; la inversión es considerablemente baja: interrelacionarse con los actores más influyentes y contenedores del nivel de confianza en la información necesaria para el viaje está a 1 paso de distancia.

Para comprobar la importancia de los actores, se tienen dos atributos más: cercanía e intermediación de los actores en la red. La primera significa los pasos necesarios que un actor debe dar para estar más cerca o más lejos de la totalidad de los integrantes de la red. El actor, a partir de la cercanía con el resto de la red, accede a la información que se reproduzca en la red, con mayor facilidad o dificultad, a partir de lo lejos o cerca que esté del resto de los actores. En este caso, el actor que está más cerca del total de los actores de la red es el actor 14 con 59 pasos. Se reafirma la importancia del actor 14 con la capacidad que tiene de estar más cerca que el resto de integrantes con la totalidad de integrantes de la red. 
El atributo de intermediación identifica al actor por quien atraviesa el mayor número de distancias geodésicas. Resulta fundamental este atributo, porque identifica la base de la estructura de la red; es decir, indica la capacidad que un actor tiene para conectar a varios actores. Conocer la estadística permite identificar al actor más importante, tanto para mantener la estructura conectada, como para que los actores por medio de varios pasos puedan llegar a otros actores. Es la base de las interrelaciones porque se trata de un actor que "conecta" a sus compañeros con el resto. Además, la inversión que se puede hacer para obtener la información está condicionada por la capacidad que tiene uno o varios actores para conectar al resto. En este caso el sustento de las interrelaciones recae en el actor 6, puesto que por él atraviesan 152 distancias geodésicas.

Resumiendo, los actores más importantes en la red que confirma la presencia de vínculos internacionales son los representados con los números 14 y 6 . Actores que, llegado el momento de presentarse un viaje migratorio, se consideran como contenedores de la información y son en quienes se confía al momento de establecer vínculos con los familiares, amigos, vecinos o conocidos que se encuentran viviendo en el país del norte. Se trata también de los actores con mayor influencia, puesto que las interrelaciones (intermediación y cercanía) dependen de ellos; de manera más dramática, son estos actores los causantes de que exista la red social, debido a que una estructura social depende de las interrelaciones que reproducen los actores. La dualidad ontológica de la que habla Lozares (2005) se refleja en la capacidad que tienen los individuos de la red para intercambiar servicios o bienes, a partir de una práctica objetiva y cognitiva. 
¿A qué distancia se encuentran los actores de la red de los protagónicos, en este caso los actores seis y catorce?

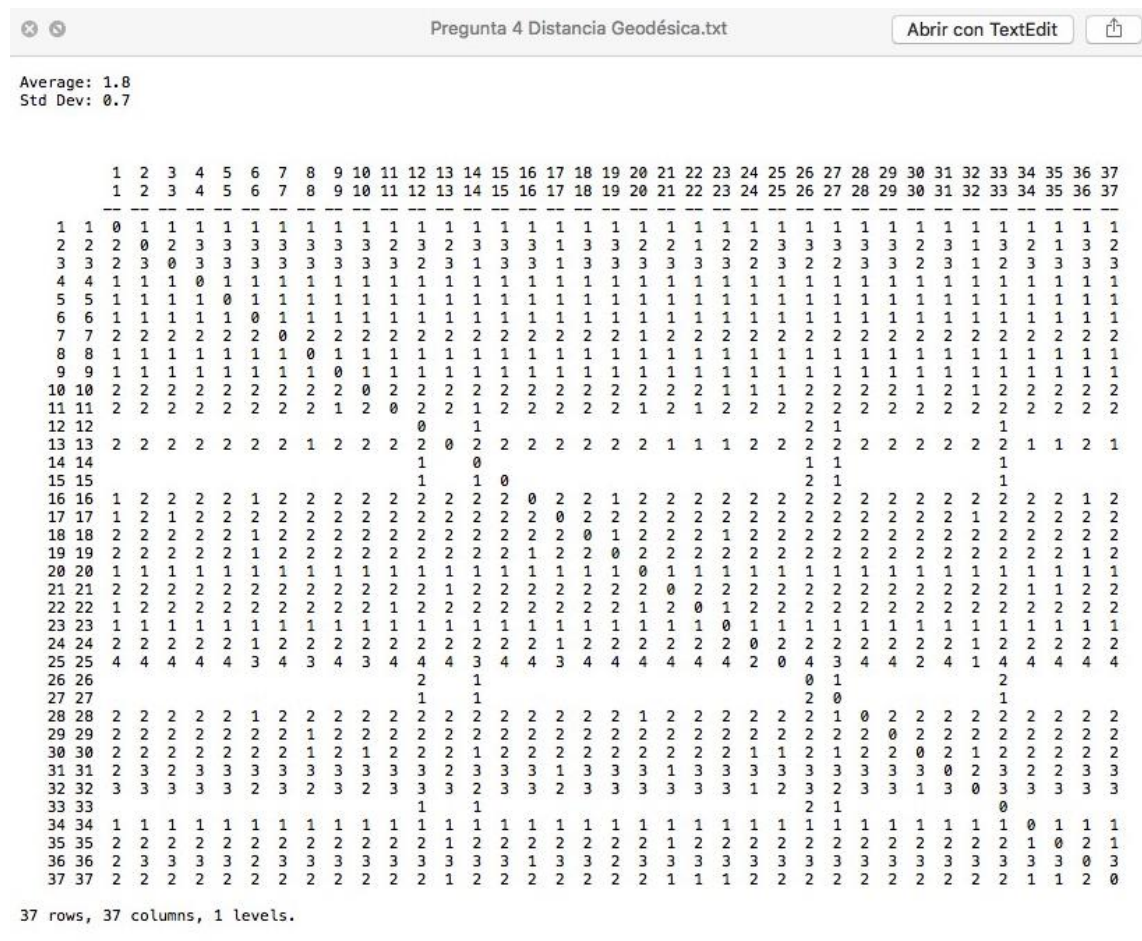

Figura 8. Distancia geodésica de la Preparatoria No. 147.

Fuente: Elaboración propia.

En la Figura 8 se resaltan a los actores 6 y 14; los números que aparecen son las distancias a las que cada actor se encuentra. Por ejemplo; el actor 1 (ubicado en la fila del lado izquierdo) se encuentra a un paso del actor $6 \mathrm{y}$ 14, respectivamente. El actor 25 se encuentra a 3 pasos de los actores con mayor influencia y prestigio social. La posible inversión que deba hacer el 
actor 25 es mayor a la que pudiera hacer el actor 1. Por lo tanto, al momento de ponderar los posibles resultados, a partir de la inversión hecha, el actor 1 tiene una relativa ventaja.

De manera complementaria se expondrán las estadísticas descriptivas del resto de las redes de información migratoria del municipio de Acambay, Estado de México (Figuras 2, 3, 4 ,5 y 6). 


\section{Tabla 4}

Estadísticas descriptivas de la red de información migratoria (presencia de vínculos internacionales)

\begin{tabular}{|c|c|c|c|c|c|}
\hline Atributo & $\begin{array}{l}\text { Prepa. } 162 \\
\text { (Fig.2) }\end{array}$ & $\begin{array}{l}\text { Sec. F. Orozco } \\
\text { Berra } \\
\text { (Fig.3) }\end{array}$ & $\begin{array}{l}\text { Sec. Jorge } \\
\text { Jiménez Cantú } \\
\text { (Fig. 4) }\end{array}$ & $\begin{array}{l}\text { Sec. José M. } \\
\text { Morelos } \\
\text { (Fig. 5) }\end{array}$ & $\begin{array}{l}\text { Sec. Ignacio } \\
\text { Ramírez } \\
\text { (Fig. 6) }\end{array}$ \\
\hline $\begin{array}{l}\text { Cercanía (atributo } \\
\text { individual por actor) }\end{array}$ & $\begin{array}{l}\text { El actor } 10 \text { está a } \\
120 \text { pasos del resto } \\
\text { de los integrantes de } \\
\text { la red. }\end{array}$ & $\begin{array}{l}\text { El actor } 19 \text { está a } \\
96 \text { pasos del resto } \\
\text { de los integrantes } \\
\text { de la red. }\end{array}$ & $\begin{array}{l}\text { El actor } 17 \text { está a } \\
57 \text { pasos del resto } \\
\text { de los integrantes } \\
\text { de la red. }\end{array}$ & $\begin{array}{l}\text { El actor } 12 \text { está a } 49 \\
\text { pasos del resto de } \\
\text { los integrantes de la } \\
\text { red. }\end{array}$ & $\begin{array}{l}\text { El actor } 28 \text { está a } \\
927 \text { pasos del resto } \\
\text { de los integrantes de } \\
\text { la red. }\end{array}$ \\
\hline $\begin{array}{l}\text { Distancia Geodésica } \\
\text { (atributo general e } \\
\text { individual de la red) }\end{array}$ & $\begin{array}{l}1 \text { paso: } 141 \text { posibles } \\
\text { relaciones } \\
2 \text { pasos: } 236 \\
\text { posibles relaciones }\end{array}$ & $\begin{array}{l}1 \text { paso: } 94 \\
\text { posibles } \\
\text { relaciones } \\
2 \text { pasos: } 115 \\
\text { posibles } \\
\text { relaciones }\end{array}$ & $\begin{array}{l}1 \text { paso: } 222 \\
\text { posibles } \\
\text { relaciones } \\
2 \text { pasos: } 239 \\
\text { posibles } \\
\text { relaciones }\end{array}$ & $\begin{array}{l}1 \text { paso: } 139 \text { posibles } \\
\text { relaciones } \\
2 \text { pasos: } 154 \\
\text { posibles relaciones }\end{array}$ & $\begin{array}{l}1 \text { paso: } 67 \text { posibles } \\
\text { relaciones } \\
2 \text { pasos: } 80 \text { posibles } \\
\text { relaciones }\end{array}$ \\
\hline \multirow{3}{*}{$\begin{array}{l}\text { Grado (atributo } \\
\text { individual por actor) }\end{array}$} & & & & \multicolumn{2}{|l|}{$\begin{array}{l}\text { Actor 20: } 10 \\
(\text { InDegree })+4 \\
(\text { OutDegree })=\text { Grado }\end{array}$} \\
\hline & $\begin{array}{l}\text { Actor 10: } 19 \\
\text { (InDegree) }+1 \\
(\text { OutDegree) }=\text { Grado } \\
20\end{array}$ & $\begin{array}{l}\text { Actor 19: } 12 \\
(\text { InDegree) }+1 \\
\text { (OutDegree)= } \\
\text { Grado } 13\end{array}$ & $\begin{array}{l}\text { Actor 17: } 18 \\
\text { (InDegree) }+4 \\
\text { (OutDegree) }= \\
\text { Grado } 22\end{array}$ & $\begin{array}{l}14 \\
\text { Actor 13: } 10 \\
\text { (InDegree) }+2 \\
\text { (OutDegree) }=\text { Grado }\end{array}$ & $\begin{array}{l}\text { Actor 28: } 12 \\
(\text { InDegree })+3 \\
(\text { OutDegree })=\text { Grado } \\
15\end{array}$ \\
\hline & $\begin{array}{l}\text { Actor } 8: 10 \\
\text { (InDegree) }+7 \\
(\text { OutDegree })=\text { Grado } \\
17\end{array}$ & $\begin{array}{l}\text { Actor 5: } 1 \\
(\text { InDegree })+6 \\
(\text { OutDegree })= \\
\text { Grado } 7\end{array}$ & $\begin{array}{l}\text { Actor 33: } 7 \\
(\text { InDegree })+7 \\
(\text { OutDegree })= \\
\text { Grado } 14\end{array}$ & $\begin{array}{l}12 \\
\text { Actor } 14: 1 \\
\text { (InDegree) }+9 \\
\text { (OutDegree) }=\text { Grado } \\
10\end{array}$ & $\begin{array}{l}\text { Actor 22: } 2 \\
(\text { InDegree })+5 \\
(\text { OutDegree })=\text { Grado } \\
7\end{array}$ \\
\hline $\begin{array}{l}\text { Intermediación } \\
\text { (atributo individual } \\
\text { por actor) }\end{array}$ & $\begin{array}{l}436 \text { distancias } \\
\text { geodésicas que } \\
\text { atraviesan por el } \\
\text { Actor } 3 \text {. }\end{array}$ & $\begin{array}{l}208 \text { distancias } \\
\text { geodésicas que } \\
\text { atraviesan por el } \\
\text { Actor } 27\end{array}$ & $\begin{array}{l}390 \text { distancias } \\
\text { geodésicas que } \\
\text { atraviesan por el } \\
\text { Actor } 25\end{array}$ & $\begin{array}{l}158 \text { distancias } \\
\text { geodésicas que } \\
\text { atraviesan por el } \\
\text { Actor } 15\end{array}$ & $\begin{array}{l}43 \text { distancias } \\
\text { geodésicas que } \\
\text { atraviesan por el } \\
\text { Actor } 28\end{array}$ \\
\hline $\begin{array}{l}\text { Densidad (atributo } \\
\text { general de la red) }\end{array}$ & $\begin{array}{l}20.9 \text { por ciento de } \\
\text { un total de } 263 \\
\text { posibles relaciones }\end{array}$ & $\begin{array}{l}8.4 \text { por ciento de } \\
\text { un total de } 94 \\
\text { posibles } \\
\text { relaciones }\end{array}$ & $\begin{array}{l}16.7 \text { por ciento de } \\
\text { un total de } 222 \\
\text { posibles } \\
\text { relaciones }\end{array}$ & $\begin{array}{l}19.8 \text { por ciento de } \\
\text { un total de } 139 \\
\text { posibles relaciones }\end{array}$ & $\begin{array}{l}4.7 \text { por ciento de un } \\
\text { total de } 67 \text { posibles } \\
\text { relaciones }\end{array}$ \\
\hline $\begin{array}{l}\text { Grado medio } \\
\text { (atributo general de la } \\
\text { red) }\end{array}$ & $\begin{array}{l}3.9 \text { relaciones por } \\
\text { actor }\end{array}$ & $\begin{array}{l}2.7 \text { relaciones por } \\
\text { actor }\end{array}$ & $\begin{array}{l}6 \text { relaciones por } \\
\text { actor }\end{array}$ & $\begin{array}{l}5.1 \text { relaciones por } \\
\text { actor }\end{array}$ & $\begin{array}{l}1.6 \text { relaciones por } \\
\text { actor }\end{array}$ \\
\hline $\begin{array}{l}\text { Centralidad (atributo } \\
\text { general de la red) }\end{array}$ & $\begin{array}{l}\text { InDegree } 34.3 \\
\text { OutDegree } 81.3\end{array}$ & $\begin{array}{l}\text { InDegree } 28.8 \\
\text { OutDegree } 94.3\end{array}$ & $\begin{array}{l}\text { InDegree } 34.2 \\
\text { OutDegree } 85.6\end{array}$ & $\begin{array}{l}\text { InDegree } 19.3 \\
\text { OutDegree } 83.2\end{array}$ & $\begin{array}{l}\text { InDegree } 26.5 \\
\text { OutDegree } 8.6\end{array}$ \\
\hline
\end{tabular}

\section{Nota: Elaboración propia.}


Dos de los elementos importantes a resaltar es la densidad general de la red (densidad) y el promedio de posibles relaciones con las que cuenta cada actor en su respectiva red (grado medio). Las estadísticas descriptivas permiten identificar a los actores con mayor influencia y prestigio social; actores que posibilitan las interrelaciones y también el acceder a la información migratoria contenida en la red: interacción y hecho social como dualidad ontológica de las redes de información migratoria, a partir de vincularse con la familia, amigos, vecinos o conocidos que viven en Estados Unidos.

Parte sustancial para identificar a los actores más importantes es determinar la centralidad de la red (centralidad Indegree = prestigio social; centralidad OutDegree $=$ influencia sobre la red). A partir de la "dependencia" de la red, tanto de prestigio social como de influencia, se puede analizar el grado de los actores, para identificar a los actores con mayor prestigio e influencia social de cada red (Grado= InDegree+OutDegree).

Una vez identificado a los actores más influyentes, se debe comprobar si las interrelaciones sociales dependen realmente de ellos. En este caso, se toman en cuenta los atributos de centralidad e intermediación. 
Lo que se pretende con este documento es ofrecer una propuesta metodológica para analizar las redes sociales de adolescentes en un contexto migratorio. El dimensionar el alcance de estas podría llevar a entender la "crisis humanitaria" de los menores migrantes que viajan solos o acompañados. Lo anterior responde a una necesidad teórica y metodológica del fenómeno migratorio: la realidad ha rebasado a la teoría y nos encontramos en una cotidianidad que exige diferentes propuestas de análisis para abordar el fenómeno migratorio.

Una "crisis humanitaria" contiene repercusiones locales que podrían modificar un espacio fronterizo. El artículo se centró en uno de los actores más susceptibles a experimentar situaciones de vulnerabilidad en el proceso migratorio. Su misma condición como actores activos en el proceso migratorio se reproduce exponencialmente, si no cuentan con la información necesaria o si siguen las pistas de una información tergiversada que podría poner en riesgo su integridad.

En este artículo se parte de que el adolescente es un actor contenido en diferentes estados de vulnerabilidad: ser menor de edad (18 años cumplidos), ser migrante (viajar sin la documentación expedita) y viaja solo. El primer punto se refiere a la condición legal que el actor tiene aun estando en suelo mexicano: ser tratado legalmente como menor de edad. Esta condición pudiera ser una característica para llevar a cabo acciones que están en contra de su voluntad. Al ser tratados como menores de edad y estar en suelo fronterizo, las organizaciones delictivas pudieran captarlos para trabajar como guías en el cruce hacia Estados Unidos o para el trasiego de droga al vecino país. Si un menor de edad es detenido en el cruce sin la

\section{A manera de conclusión}


documentación expedita, el proceso legal se enfoca en una repatriación hacia México o hacia país de origen.

El segundo estado de vulnerabilidad, ser migrante sin la documentación expedita, implica una repatriación involuntaria y forzada. El tercer elemento de vulnerabilidad se suma para hacer al actor más susceptible a realizar acciones que comprometen su integridad; el hecho de viajar solo implica un total desconocimiento de la dinámica fronteriza; puede ser extorsionado, engañado y amenazado para realizar cualquier trabajo.

El análisis de las redes sociales en un contexto migratorio, como el que se expuso en este artículo, significaría que se podría ubicar al responsable directo de las interrelaciones que se reproducen en una red. Es aquel actor por la que la red se mantiene conectado y por el que fluye toda la información y peso la red; el que puede desarticular a la red o el que puede filtrar la información que se reproduce.

En un determinado caso, elementos como las estadísticas descriptivas permitirían desarticular una red que pone en riesgo la integridad de los actores, en tanto están reproduciendo información tergiversada. También, podría generar una oportunidad para reproducir información valiosa que verdaderamente ayude a los actores, en caso de encontrarse en una situación que no se había planeado: ¿Qué hacer si es detenido por la Control Border Patrol (CBP)?, ¿a qué instituciones de la sociedad civil podría acercarse si llegara a necesitar ayuda?, ¿qué derechos tiene a partir de su condición de adolescente migrante que viaja solo? Información que resulta fundamental cuando inicia un viaje migratorio sin la documentación expedita. 
Imaginemos por un segundo que los actores con mayor influencia y prestigio social de cada red son individuos que escucharon decir a alguien que cualquier niño, niña o adolescente que llegue a Estados Unidos tendrá asilo político. El alcance y capacidad de influencia que contiene sobre la red sería suficiente para llegar a cada uno de los actores. En este punto no importa el tipo de información (si es verídica o no); lo que realmente importa es realizar la menor inversión posible para obtener la información, puesto que se está en una situación de precariedad de la que se requiere salir de manera inmediata. Cualquier tipo de información que se pueda obtener con la menor cantidad de inversión, resulta un oasis para quienes están muriendo de sed.

En conclusión, existen un sin fin de características morfológicas del fenómeno migratorio de los adolescentes y falta mucho por realizar. Sobre todo, si se piensa que el proceso migratorio implica una movilidad, una migración como tal y, por supuesto; un retorno. Lo que se pretende es dejar constancia de que la realidad ha rebasado las diferentes propuestas teóricas y metodológicas que han venido abordando el proceso migratorio de niñas, niños y adolescentes.

Asimismo, el proceso para obtener información mediante la posibilidad de interrelacionarse con los vínculos internacionales que contiene la red implica una inversión que tienen que desarrollar los actores. Conocer el costo que implica interrelacionarse significa que existe un principio de ponderación entre inversión y posible resultado. 
Abello-Llanos, R. y Madariaga-Orozco, C. (2003). Las redes sociales Referencias ¿Para qué? Colombia: Editado por la Universidad del Norte.

Aguirre, L. J. (2011). Introducción al análisis de redes sociales. Documento de trabajo No. 82. Buenos Aires: Centro Interdisciplinario para el Estudio de políticas Públicas (Ciepp).

Ángel-Pérez, A. L. y Rebolledo Martínez, A. (2009). Familia, remesas y redes sociales en torno a la migración en Veracruz central. Estudios fronterizos, 10 (19), pp. 9-48.

Arango, J. (2005). La explicación teórica de las migraciones: Luz y Sombra. Migración y Desarrollo. Latinoamericanistas, 001, pp. 130.

Bolíbar, M. (2011). Las asociaciones en las redes personales ¿Mecanismo de integración de la población inmigrante? REDES, Revista Hispana para el análisis de redes sociales, 20 (7), pp. 161-187. http://dx.doi.org/10.5944/empiria.26.2013.7154

Carnet, P. (2011). Estrategias de activación y construcción de redes sociales en la migración. El ejemplo de los migrantes africanos clandestinizados en la frontera sur española. REDES Revista hispana para el análisis de redes sociales, $20\left(10^{\mathrm{a}}\right)$, pp. 232-250. Recuperado de: http://revista-redes.rediris.es $/ \mathrm{html}$ vol20/vol20_10es.htm

De Miguel Luken, V. (2006). Reseña de las Redes Sociales de los Migrantes extranjeros en España de R. Aparicio y A. Tornos. REDES, Revista Hispana para el análisis de Redes Sociales, 11 (10), 1-10. Recuperado de: http://www.redalyc.org/articulo.oa?id=93101110

Díaz, L. M. (2009). La construcción de redes sociales y su impacto en las migraciones. Diálogos Migrantes. Revista del Observatorio colombo-ecuatoriano de migraciones OCEMI, 3, pp. 8-18. Recuperado de http://observatoriodemigraciones.org/apc-aafiles/69e3909999fd8ec8018dd3f5d7dbdc5d/DMigrantes_No.3.pdf 
Gallo-Campos, K. (2005). Niñez migrante: blanco fácil para la discriminación. Ponencia presentada en el Seminario Internacional Sobre los Derechos Humanos de los Migrantes. Boca del Río, Veracruz.

Giner, Salvador. 2014. Georg Simmel. El origen de la sociología analítica relacional. Barcelona: UOC.

Giorguli-Saucedo, S. E. Y Gutiérrez Vázquez, E. Y. (2011). Niños y jóvenes en el contexto de la migración internacional entre México y Estados Unidos. Coyuntura Demográfica, 1, pp. 21-25. Recuperado de http://www.redalyc.org/pdf/112/11232148008.pdf

Goycochea, A. y Ramírez-Gallegos, F. (2002). Se fue ¿A volver? Imaginarios, Familia y Redes Sociales en la Migración Ecuatoriana a España (1997-2000). Iconos, Revista de Ciencias Sociales, 14, pp. 24-29. Recuperado de http://www.redalyc.org/articulo.oa?id=50901404

Herrera-Lima, F. F.; Calderón Marillón, Ó. y Hernández Valdovinos, L. (2007). Redes que comunican y redes que enclaustran: evidencia de tres circuitos migratorios contrastantes. Migración y Desarrollo, 8, pp. 3-23. Recuperado de http://www.izt.uam.mx/poes/fernando_herrera_mig_dso.pdf

López-Castro, G. (2005). Niños, socialización y migración a Estados Unidos en Michoacán. Ponencia presentada en la Conferencia Internacional Perspectivas mexicanas y estadounidenses en el estudio de la migración internacional, 27-29 enero. Taxco, Guerrero.

Lozares-Colina, C. (2005). Bases socio-metodológicas para el Análisis de Redes Sociales, ARS. EMPIRIA. Revista de Metodología de Ciencias Sociales, 10, pp. 9-35. Recuperado de: http://www.redalyc.org/articulo.oa?id=297123998001

Lozares, C y Verd, J. M. (2011). De la Homofilia a la Cohesión social y viceversa. REDES, Revista Hispana para el análisis de redes sociales, 20 (2), pp. 29-59. Recuperado de http://revistaredes.rediris.es/html-vol20/vol20_2.htm 
Luna, M. (2004). Redes sociales. Revista Mexicana de Sociología, 66 (No. Especial), pp. 59-75. Recuperado de: http://www.jstor.org/stable/3541443?seq=1\#page_scan_tab_conten ts

Massey, D. S; Arango, J.; Hugo, G.; Kovaochi, A.; Pallermo, A. y Taylor, J.E. (1998). Una evaluación de la teoría de la migración internacional. El caso de América del Norte. En Malgesini, G. (compilador). Cruzando Fronteras. Migraciones en el sistema mundial (pp. 425-450). Madrid: Ícara, Fundación hogar del empleo.

Mummert, G. (2009). Siblings by telephone: experiences of Mexican Children in long distance childreading arrangments. Journal of the Southwest, 51 (4), pp. 503-521. Recuperado de: http://www.jstor.org/stable/40599706?seq=1\#page_scan_tab_conte nts

Pineda-Pérez, S. Y Aliño Santiago, M. (2009). El concepto de Adolescencia. En MINSAP (compilador). Manual de Prácticas Clínicas para la atención integral a la Salud en la Adolescencia (pp 15-23). La Habana: MINSAP.

Pérez Monterosas, M. (2003). Las Redes Sociales en la Migración Emergente de Veracruz a los Estados Unidos. Migraciones Internacionales, 2 (1), pp. 106-136.

Rodríguez, J. A. (2004). La Red terrorista del 11M. Reis, 107 (04), 155179. Recuperado de: http://www.arschile.cl/moodledata/2/Mod2/AplicacionesARS/Red11M.pdf

Valdéz-Gardea, G. C. (2011). Movilización, migración y retorno de la niñez migrante. Ponencia presentada en el Tercer Encuentro Internacional de Niñez Migrante. Hermosillo, Sonora.

Valdéz-Gardea, G. C. (2008ª). Achicando Futuros; actores y lugares de la migración. Hermosillo: El Colegio de Sonora.

Valdéz-Gardea, G. C. (2008b). Revisando la Antropología de la migración: frontera, actores y trabajo de campo. En G.C. Valdéz-Gardea (coordinadora). Achicando futuros. Actores y Lugares de la migración (pp.). Hermosillo: El Colegio de Sonora. 
"Crisis humanitaria": El rol de las redes sociales...

Velázquez-Álvarez, O. A. y Aguilar-Gallegos, N. (2005). Manual introductorio al análisis de redes sociales. Ejemplos prácticos con UCINET 6.85 y NETDRAW 1.48. Medidas de centralidad. Toluca: Universidad Autónoma del Estado de México.

Villaseñor, B. y J. Moreno (coordinadores) (2006). La esperanza truncada: menores migrantes deportados por la garita Mexicali-Caléxico. Mexicali: Academia Mexicana de Derechos Humanos.

Wellman, B. (2000). El análisis estructural: del método y la metáfora a la teoría y la sustancia. Canadá: Universidad de Toronto. 
1. Es un programa computacional que se caracteriza por contener docenas de rutinas analíticas para redes. Permite el análisis general y multivariado, contiene herramientas para crear escalas multidimensionales, análisis de correspondencia, análisis de factores, de grupos y de regresión múltiple. Posee una plataforma para el manejo de datos y herramientas de transformación para realizar procedimientos de teoremas gráficos con un lenguaje algebraico interpuesto por matrices (Velázquez \& Aguilar, 2005, p. 44).

2. Las tres definiciones se pueden consultar en la obra de Aguirre, L. J. (2011). Introducción al análisis de redes sociales. Documento de trabajo No. 82. Buenos Aires: Centro Interdisciplinario para el Estudio de políticas Públicas (Ciepp).

3. Se parte de un análisis visual con ayuda de los mapas que resultan de utilizar el software especializado UCINET6.

4. Censo de Población y Vivienda, 2010. Recuperado de: http://www.inegi.org.mx/est/lista_cubos/consulta.aspx?p=pob\&c=1

5. InDegree: Selecciones recibidas. Se trata de los compañeros que reconocen al actor como el que tiene un vínculo en Estados Unidos.

6. OutDegree: Selecciones hechas. Se trata cuando el actor selecciona a los compañeros que sabe tienen un vínculo en Estados Unidos.

7. Se pondera un nivel de confianza alto cuando la densidad supera el $60 \%$.

\section{Recibido: 24-noviembre-2015 Aceptado: 20-febrero-2016}

Todos los derechos reservados. Universidad de Costa Rica. Esta revista se encuentra licenciada con Creative Commons ReconocimientoNoComercial-SinObraDerivada 3.0 Costa Rica. (CC BY-NC-SA 3.0 CR)

Correo electrónico: humanidades@ucr.ac.cr Sitio web: http://revistas.ucr.ac.cr/index.php/humanidades 